\title{
Innovative approach to design a new national low speed wind tunnel
}

\author{
${ }^{1 *}$ M. Abbaspour; ${ }^{2}$ M. N. Shojaee \\ ${ }^{1}$ Department of Mechanical Engineering, Sharif University of Technology \\ and Graduate School of the Environment and Energy, Science and Research Branch, IAU, Tehran, Iran \\ ${ }^{2}$ Department of Environmental Engineering, Graduate School of the Environment and Energy, \\ Science and Research Branch, Islamic Azad University, Tehran, Iran
}

Received 19 August 2008; $\quad$ revised 25 September 2008; accepted 24 Novmber 2008; avaLDle online 10 December 2008

\begin{abstract}
A new multipurpose wind tunnel with adjustable test section designed in the science and research branch of Islamic Azad University site could be used either as the environmental, subsonic or climatic wind tunnels. For this purpose, a new design approach was adopted in which through the adjustment of the wind tunnel cycle, i.e. the nozzle of test section,it could be utilized as any of the three wind tunnels. A design used for environmental wind tunnels and other contraction which was adjusted by $50 \%$ through changes in the polynomial contraction for other applications. As a result, the best fitted profile for the environmental wind tunnels contraction was selected by contraction best fit program. Consequently, the flow properties and flow separation of contractions were analyzed by the computational fluid dynamics model in a computer software. This method is also suitable for existing low speed wind tunnels with special applications.
\end{abstract}

Key words: Nozzle, environmental, subsonic, climatic, pollutant

\section{INTRODUCTION}

Wind tunnels are used in many engineering and environmental applications as a key tool in understanding the problems associated with aerodynamics and transport phenomena (Bienkiewicz, 1996). The dispersion of pollutants over industrial and residential areas, the impact of lift or drag on various structures and wind loads on civil installations are examples where wind tunnel simulations can be used to understand and control the related problems (Kong and Parkingson, 1997; Cermak and Takeda, 1985).

This study introduces a new multipurpose wind tunnel with an adjustable test section designed for environmental, subsonic and climatic studies at Science and Research Branch of Islamic Azad University.

The main application of this apparatus is for the environmental wind tunnel (EWT) studies.The length and the width of the test section are $28 \mathrm{~m}$ and $2.5 \mathrm{~m}$, respectively. The height of the mounting turntable varies from $1.5 \mathrm{~m}$ up to $2.2 \mathrm{~m}$. It could also be used as a subsonic wind tunnel (SWT) or a climatic wind tunnel (CWT) if the dimensions of the test section change to $1.5 \mathrm{~m} \times 1.5 \mathrm{~m}$ or $2.28 \mathrm{~m} \times 2.2 \mathrm{~m}$, respectively. One of

*Corresponding Author Email: m-abbaspour@jamejam.net Tel.: +9821 4486 5005; Fax: +9821 44865002 the characteristic features of this tunnel is the contraction nozzle which length is $7.3 \mathrm{~m}$. In order to change the wind tunnel application, a new method is introduced for changing the fraction part of contraction and the test section of wind tunnel.

\section{Wind tunnel design features}

In this section, the wind tunnel design features (Pankharst and Holder, 1952; Bradshaw and Pankharst, 1964; Rae and Pope, 1984; Barlow et al., 1999) of all EWT cycle were discussed. The SWT and CWT cycles are the same as EWT for most parts except for some parts of test section and nozzle.

\section{Test section}

In the EWT ceiling and floor, some provisions were made for illumination and a turn table were installed in the floor of the test section. The turntable was driven by a motor and the yaw angles could be measured easily. The roof had special exchangeability since a rain generating system and a sun simulator were installed in two alternative roof sections.

At the end of the test section, an open area was designed to generate the rain. It was suggested by 
Barlow et al., 1999 to use wind tunnel in its open cycle for this purpose. For producing water droplets of a certain size distribution, a preparation chamber above the tunnel was required. The final size distribution was determined after the droplets passed through the mixing zone between the exit edge in the roof and a collector at the downstream end of the roof opening section.

The long roof section of EWT was designed to allow a sun simulator installation as a replacement for standard roof section. Using two types of lamps, the light power could be controlled in the range of 600 to 1200 watt/sq.m.

Considering the atmospheric boundary layer (ABL) depth in the range of 300-500 m, choice the minimum boundary layer thickness of $0.5 \mathrm{~m}$ for the clean tunnel configuration (smooth boundary and no initial momentum sinks) (Cook, 1982; Hughes and Bohm, 2000) results in a practical range for the model length scale of $1: 600$ to $1: 1000$. A boundary layer wind tunnel (BLWT) designed to achieve this flow condition is extremely versatile in practice, since much thicker boundary layers will be develop over a rough boundary with or without initial momentum sinks (Cermak et al.,1995; Schatzmann et al, 1995; Garg et al., 1997).

The required test section length for neutral flow can be estimated (for the clean configuration and zero pressure gradients) using the Schlichting, (1960) equation as follow:

$$
\frac{L_{X}}{\delta}=3.47\left(\frac{\delta U_{0}}{v}\right)^{1 / 4}
$$

Eq. 1 was used to calculate a test section length of approximately $27.4 \mathrm{~m}$ for $\delta=0.5 \mathrm{~m}$ and $U_{0}=2 \mathrm{~m} / \mathrm{s}$ for the EWT. The test-section height for EWT had a nominal dimension of $2.2 \mathrm{~m}$ to accommodate the required boundary layer thickness before interacting with the roof boundary layer. Thus, the reference "long” EWT has a test-section length-to-height ratio of 14 (Cermak, 1982).

In EWT, a boundary layer with a typical depth of 0.5 $\mathrm{m}$ to $1 \mathrm{~m}$ is developed naturally over a rough floor of $27.4 \mathrm{~m}$ in length. Installing the passive devices at the test section entrance, the depth of the boundary layer can be increased. Such an artificial increase may be necessary, particularly in flow simulations over the ocean or over terrain with low or moderate roughness (White, 1996). The height of the tunnel may be adjusted to be increased slightly with downstream position. The purpose of such an adjustment is to achieve a zero pressure gradient stream wise which would otherwise be impossible owing to energy losses associated with flow friction at the walls and with internal friction due to turbulence.

However, for air pollution applications, the temperature structure of the boundary layer is an essential factor. The heating/cooling of floor and roof of the EWT test section is added to obtain a desired thermal profile at the model mounted section of the wind tunnel. The dimensions of the test sections entrance for SWT and CWT are $1.5 \mathrm{~m} \times 1.5 \mathrm{~m}$ and 2.28 $\mathrm{m} \times 2.2 \mathrm{~m}$, respectively.

\section{Corners}

Investigation of the relation between the resistance and the design of a corner shows that a corner may be designed to achieve a low resistance without the use of guide vanes (Friedman and Westphal, 1952; Nouri, 1989). The wind tunnel corners are rounded and high values will be chosen for both the ratio of curvature radius to the duct width and the ratio of height to width (Collar, 1936; Lindgren et al., 1998).

The first and second corners (Fig. 1) are located exactly after test section and after first leg, respectively and are essential due to higher speeds compared to two other corners.

The first and second corners include 15 and 19 corner vanes, respectively with $0.5 \mathrm{~m}$ cord lengths and $0.236 \mathrm{~m}$ space between them with $535 \mathrm{~N}$ lift and $270 \mathrm{~N}$ $\mathrm{m}$ leading edge momentums. The third and fourth corners are the same and include 25 corner vanes with $0.78 \mathrm{~m}$ cord length and $0.368 \mathrm{~m}$ space between them with $240 \mathrm{~N}$ lift and $9.7 \mathrm{~N}$-m leading edge momentums. Table 1 and Fig. 2 depict the corners camber profile.

\section{General specifications of EWT}

The global feature of EWT is shown in Fig. 1. In addition, the summery of EWT dimensions and parameters are presented as follows:

Velocity $=\sim 0$ to $30 \mathrm{~m} / \mathrm{sec}$

Width $=2.5 \mathrm{~m}$

Flow quantity $=165 \mathrm{cum} / \mathrm{sec}$

First corner width $=2.5 \mathrm{~m}$

First diffuser divergent angle (degree) $=2.9$

Return diffuser divergent angle (degree) $=3.5$

Third corner width $=6.47 \mathrm{~m}$

Total wind tunnel width $=15.1 \mathrm{~m}$

First diffuser length $=5.8 \mathrm{~m}$ 
Contraction ratio $=10$

Total Sp $=2.75$ in-wg

Height $=1.5$ to $2.2 \mathrm{~m}$

Length $=27.4 \mathrm{~m}$

Entrance tunnel width $=2.28 \mathrm{~m}$

First corner height $=1.85 \mathrm{~m}$

Second corner width $=3.1 \mathrm{~m}$

Second corner height $=2.45 \mathrm{~m}$

Third corner height $=5.82 \mathrm{~m}$

Total wind tunnel length $=48 \mathrm{~m}$

Contraction length $=7.3 \mathrm{~m}$

Energy ratio $=0.67$

$\mathrm{Hp}=300$

\section{Polynomial contraction}

Over the years, many authors have been interested in methods of designing low speed wind tunnel contractions (Jordinson, 1961; Morel, 1975; 1977; Downie et al., 1984; Vieira and Aparecido, 1999). In this case, several desirable characteristics of the wall profile are identified. The results were expected to be the most favorable combination of flow uniformity, thin boundary layer and negligible losses.
A fifth order polynomial (Bell and Mehta, 1988) satisfies the condition of zero, first and second derivatives at the inlet and outlet. Normalizing the length of this polynomial is as follows:

$$
\begin{aligned}
& h=\left(-10 \xi^{3}+15 \xi^{4}-6 \xi^{5}\right)\left(h_{i}-h_{o}\right)+h_{i} \\
& \xi=x / L
\end{aligned}
$$

Where, $L$ is the total length of nozzle; $h$ is the height of the nozzle at $x$ position and $h_{i}$ and $h_{o}$ are the heights of the contraction wall from its center line at the inlet and outlet, respectively.

Transformation of Eq. 2 (Brassard and Ferchichi, 2005) with reference to its first and second derivatives is as follow:

$h=\left[\left(-10 \xi^{3}+15 \xi^{4}+6 \xi^{5}\right)\left(h_{i}^{1 / \alpha}-h_{o}^{1 / \alpha}\right)+h_{i}^{1 / \alpha}\right]^{\alpha}$

Where, $\alpha$ is a constant value or the function of $\xi$ in which $0<\xi<1$.

In this study, Eq. 2 is used for EWT contraction as the main application and Eq. 3 for adjusting the nozzle length by $50 \%$ for the other applications.
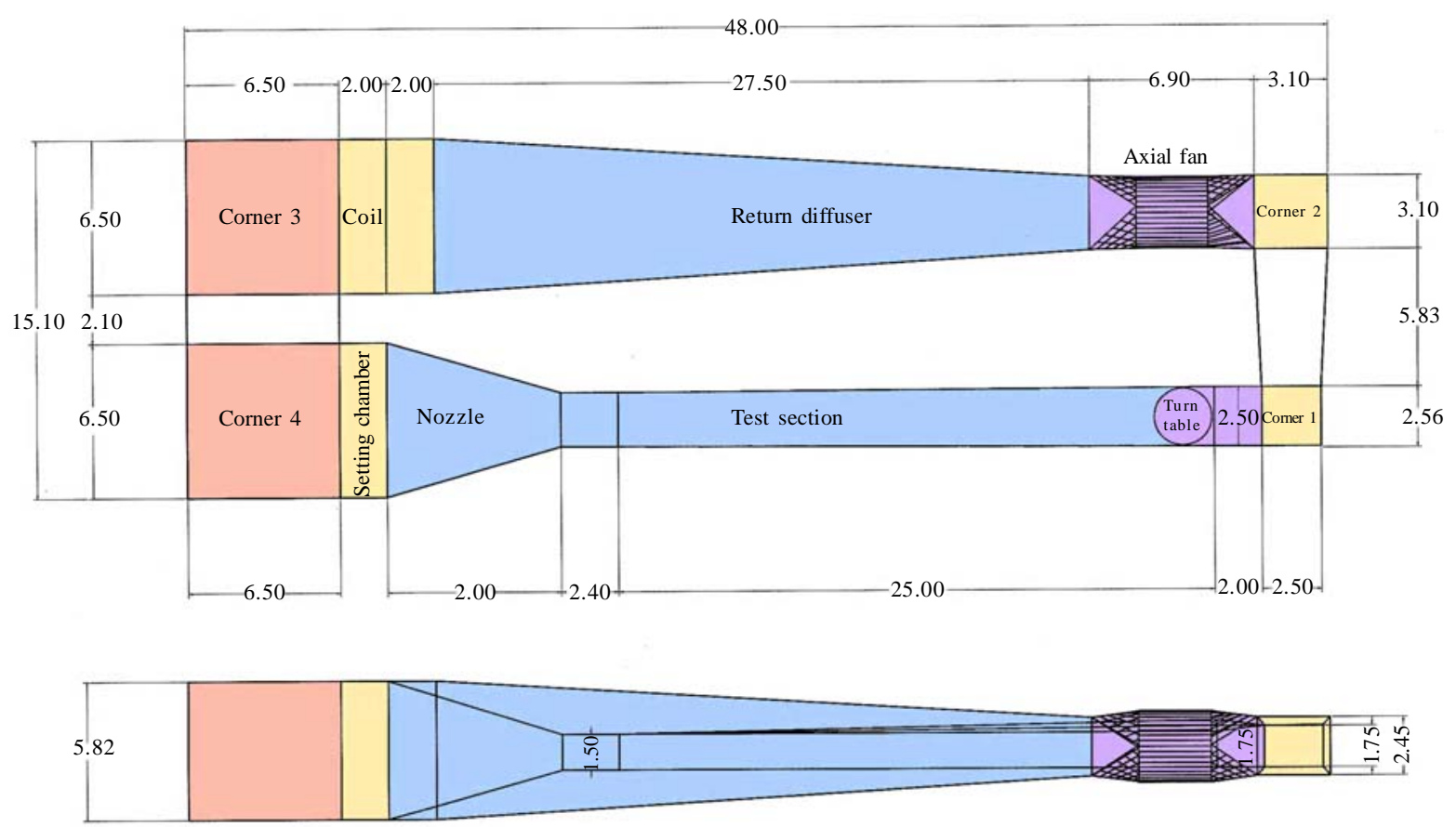

Fig. 1: The global feature of environmental wind tunnel (all dimentions in meter) 


\section{CBP computer program}

Contraction best fit program (CBP) is a $\mathrm{C}++$ computer program that is written by authors to find the best fit between two polynomial contractions with different outlets. The input data to the program is polynomial contraction with inlet, outlet and length geometries and also the desired new outlet geometries. The output of the program would be the best fit polynomial derived from Eq. 3 with selection of $\alpha$ as a parameter. The length and polynomial fit depend on the level of selected tolerance. It is recommended to use the lowest possible tolerance in reference to the total scale of the contraction.
Wind tunnel systems

EWT contraction

The shape of test section is rectangular and the flow properties are of the utmost importance in its performance (Al-Nassar et al., 2002).

The 3D rectangular contraction is developed with a length of $7.3 \mathrm{~m}$ for EWT using Eq. 2. The EWT contraction profile is presented in Table 2. Contraction roof and wall of the EWT is derived from separate boundary conditions in the Eq. 2 as shown in Fig. 3a. The range of the roof and the wall contraction are $6.5 \mathrm{~m}$ to $2.28 \mathrm{~m}$ and $5.82 \mathrm{~m}$ to $1.5 \mathrm{~m}$, respectively.

Table 1: Corners camber profiles (all dimensions experessed in meter)

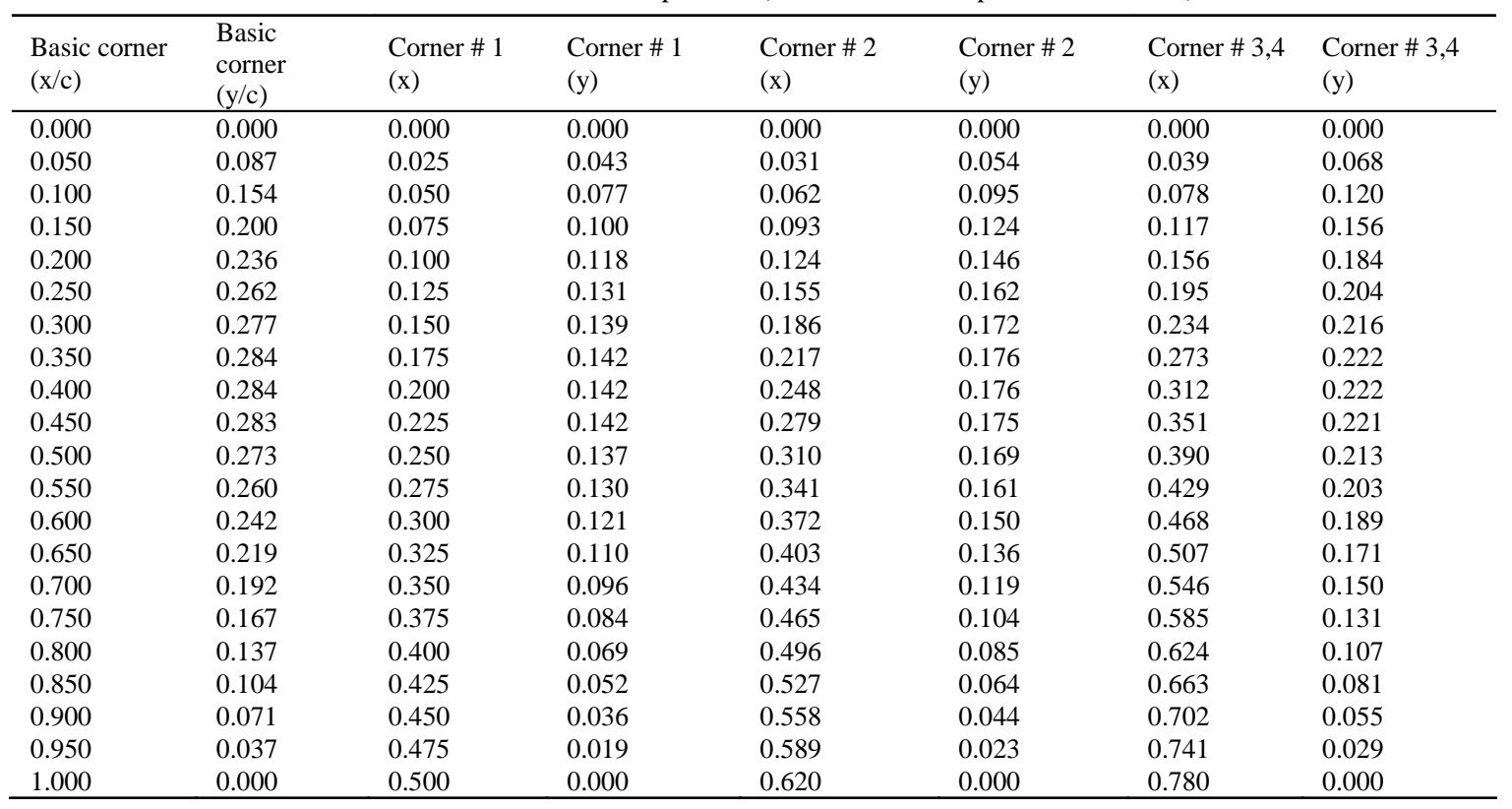

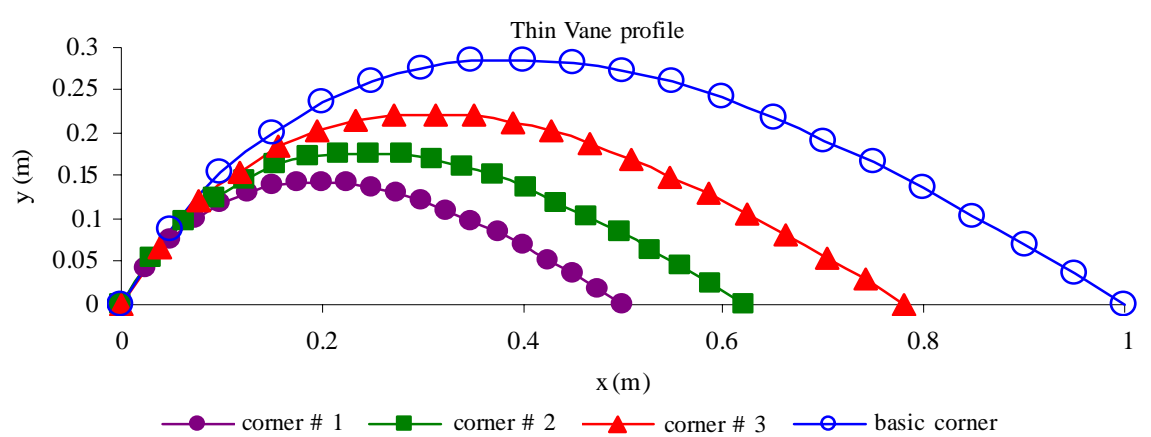

Fig. 2: Corners camber profile (all dimensions are in meter) 
Int. J. Environ. Sci. Tech., 6 (1), 23-34, Winter 2009

Table 2: EWT contraction profile

\begin{tabular}{ccccccccc}
\hline & EWT contraction & & \multicolumn{3}{c}{ EWT contraction } & \multicolumn{3}{c}{ EWT contraction } \\
\hline $\mathrm{X}$ & Wall & Roof & $\mathrm{X}$ & Wall & Roof & $\mathrm{X}$ & Wall & Roof \\
0.0 & 2.9100 & 3.2500 & 2.6 & 2.3812 & 2.7334 & 5.2 & 1.0679 & 1.4505 \\
0.2 & 2.9096 & 3.2496 & 2.8 & 2.2848 & 2.6393 & 5.4 & 0.9976 & 1.3819 \\
0.4 & 2.9067 & 3.2468 & 3.0 & 2.1831 & 2.5399 & 5.6 & 0.9364 & 1.3221 \\
0.6 & 2.8994 & 3.2397 & 3.2 & 2.0771 & 2.4364 & 5.8 & 0.8844 & 1.2713 \\
0.8 & 2.8860 & 3.2266 & 3.4 & 1.9683 & 2.3301 & 6.0 & 0.8417 & 1.2296 \\
1.0 & 2.8653 & 3.2063 & 3.6 & 1.8577 & 2.2221 & 6.2 & 0.8082 & 1.1969 \\
1.2 & 2.8362 & 3.1779 & 3.8 & 1.7469 & 2.1138 & 6.4 & 0.7834 & 1.1726 \\
1.4 & 2.7981 & 3.1407 & 4.0 & 1.6370 & 2.0065 & 6.6 & 0.7664 & 1.1560 \\
1.6 & 2.7508 & 3.0945 & 4.2 & 1.5295 & 1.9014 & 6.8 & 0.7562 & 1.1461 \\
1.8 & 2.6941 & 3.0391 & 4.4 & 1.4255 & 1.7998 & 7.0 & 0.7514 & 1.1414 \\
2.0 & 2.6283 & 2.9749 & 4.6 & 1.3263 & 1.7029 & 7.2 & 0.7501 & 1.1401 \\
2.2 & 2.5538 & 2.9021 & 4.8 & 1.2330 & 1.6118 & 7.3 & 0.7500 & 1.1400 \\
2.4 & 2.4712 & 2.8213 & 5.0 & 1.1465 & 1.5274 & & & \\
\hline
\end{tabular}

Table 3: SWT contraction profile

\begin{tabular}{ccccccccc}
\hline \multicolumn{3}{c}{ Subsonic WT contraction } & \multicolumn{3}{c}{ Subsonic WT contraction } & \multicolumn{3}{c}{ Subsonic WT contraction } \\
\hline $\mathrm{X}$ & Wall & Roof $(1.418)$ & $\mathrm{X}$ & Wall & Roof $(1.418)$ & $\mathrm{X}$ & Wall & Roof $(1.418)$ \\
0.0 & 2.9100 & 3.2500 & 2.6 & 2.3812 & 2.7420 & 5.2 & 1.0679 & 1.2358 \\
0.2 & 2.9096 & 3.2496 & 2.8 & 2.2848 & 2.6452 & 5.4 & 0.9976 & 1.1364 \\
0.4 & 2.9067 & 3.247 & 3.0 & 2.1831 & 2.5414 & 5.6 & 0.9364 & 1.0466 \\
0.6 & 2.8994 & 3.2402 & 3.2 & 2.0771 & 2.4314 & 5.8 & 0.8844 & 0.9678 \\
0.8 & 2.8860 & 3.2277 & 3.4 & 1.9683 & 2.3162 & 6.0 & 0.8417 & 0.9011 \\
1.0 & 2.8653 & 3.2084 & 3.6 & 1.8577 & 2.1966 & 6.2 & 0.8082 & 0.8472 \\
1.2 & 2.8362 & 3.1811 & 3.8 & 1.7469 & 2.0740 & 6.4 & 0.7834 & 0.8063 \\
1.4 & 2.7981 & 3.1454 & 4.0 & 1.6370 & 1.9493 & 6.6 & 0.7664 & 0.7779 \\
1.6 & 2.7508 & 3.1008 & 4.2 & 1.5295 & 1.8240 & 6.8 & 0.7562 & 0.7607 \\
1.8 & 2.6941 & 3.0469 & 4.4 & 1.4255 & 1.6992 & 7.0 & 0.7514 & 0.7524 \\
2.0 & 2.6283 & 2.9839 & 4.6 & 1.3263 & 1.5766 & 7.2 & 0.7501 & 0.7501 \\
2.2 & 2.5538 & 2.9119 & 4.8 & 1.2330 & 1.4574 & 7.3 & 0.7500 & 0.7500 \\
2.4 & 2.4712 & 2.8311 & 5.0 & 1.1465 & 1.3433 & & & \\
\hline
\end{tabular}

\section{MATERIALS AND METHODS}

The identification of contraction's flow properties is highly important (Sargison et al., 2004).

For this reason, a 3D grid generation of contraction profile is prepared and solved by computational celloid dynamic (CFD) method in computer software (Fluent). The contraction profile schemes shown in Figs. 3 a, b and c are the pressure and velocity vectors of EWT, respectively. In Fig. 4 the total schematics of EWT and its nozzle application are shown from two different views.

\section{SWT contraction}

For subsonic wind tunnel test section, cross section of contraction outlet was $1.5 \mathrm{~m} \times 1.5 \mathrm{~m}$. This 

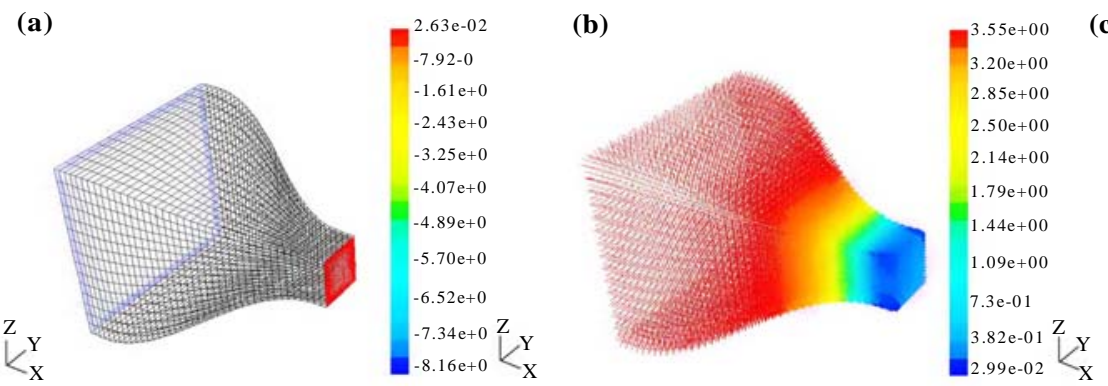

(c)

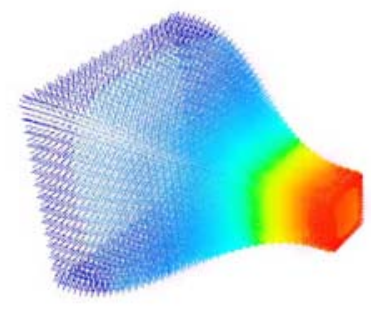

Fig. 3: a) Grid generation for environmental wind tunnel contraction; b) EWT velocity vectors colored by static pressure (Pascal); c) EWT velocity vectors colored by velocity magnitude $(\mathrm{m} / \mathrm{s})$
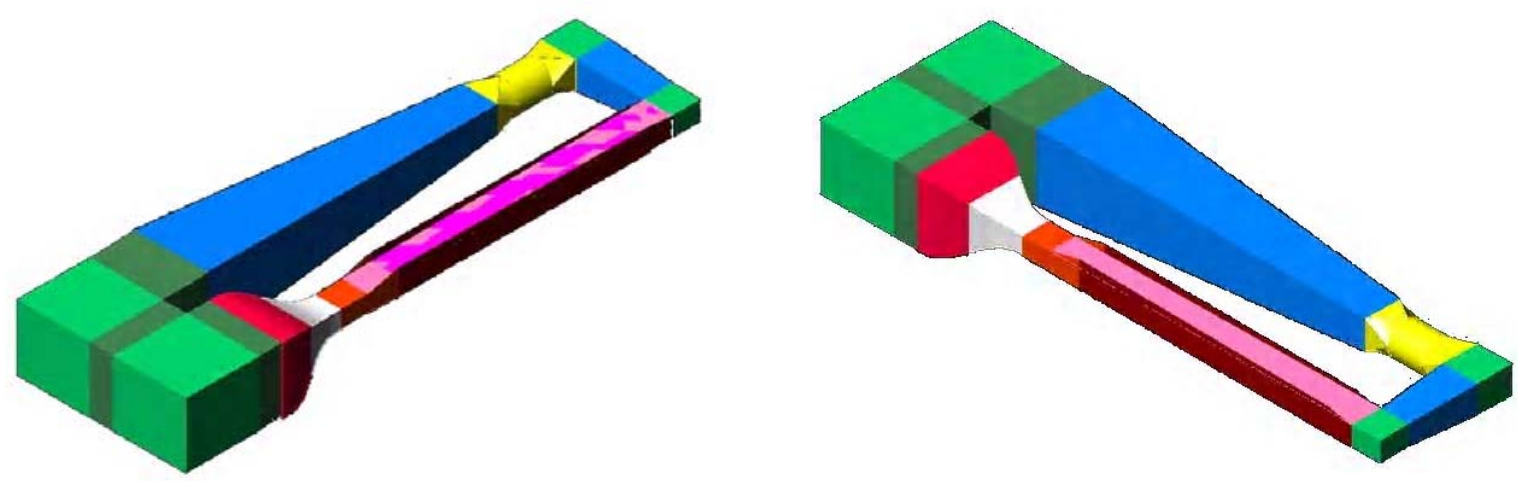

Fig. 4: Designed environmental wind tunnel

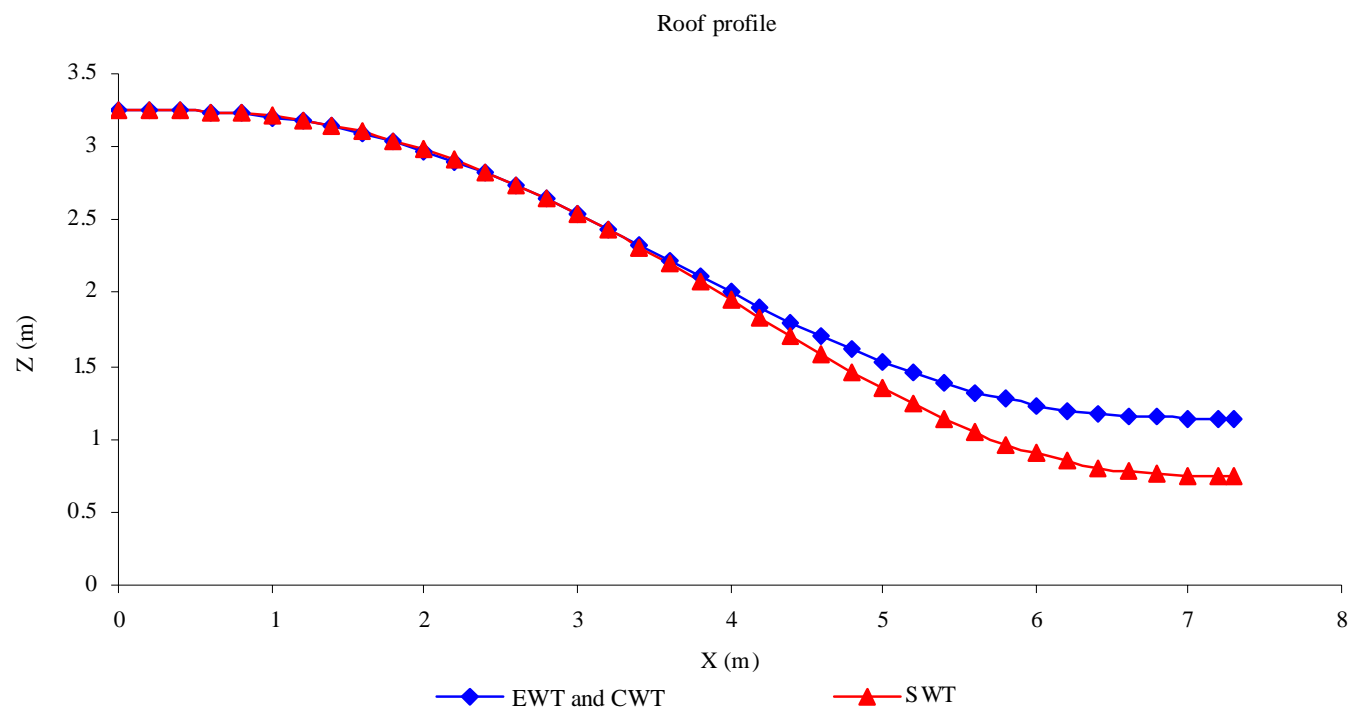

Fig. 5: Roof profile of EWT, CWT and SWT. (EWT and CWT profile are the same and SWT profile is fitted to the first part of the EWT profile) 
means that the wall profile was the same as the profile of EWT (wall profile of EWT is from $5.82 \mathrm{~m}$ to $1.5 \mathrm{~m}$ ), but the roof profile had to be accommodated to $1.5 \mathrm{~m}$ If Eq. 2 was used to develop the roof profile, the whole contraction could be changed for SWT application. Changing the tunnel contraction completely and replacing it with another suitable contraction for subsonic usage is rather difficult.

Thus, it is logical to replace a portion of EWT nozzle and adjust part of the test section to make it suitable for subsonic usage. Through this process, Eq. 3 is used in CBP computer program for selecting the best fitted profile for SWT contraction. The contraction roof profile of subsonic wind tunnel is obtained using Eq. 3 for $\alpha=1.418$. The following mathematical equation is the roof profile for SWT (Eq. 4) where the wall profile is the same as EWT. The profile dimensions are shown in Table 3:

$h=\left[\left(-10 \xi^{3}+15 \xi^{4}+6 \xi^{5}\right)\left(h_{i}^{0.705}-h_{o}^{0.705}\right)+h_{i}^{0.705}\right]^{1.418}$

As illustrated in Fig. 5, first portion of the SWT roof profile exactly fits the EWT roof profile. This portion is about $50 \%$ of contraction length (3.6 $\mathrm{m}$ of $7.3 \mathrm{~m}$ of total contraction length). Thus the SWT contraction profile is as follows:

$$
h=\left\{\begin{array}{l}
\left(-10 \xi^{3}+15 \xi^{4}-6 \xi^{5}\right)\left(h_{i}-h_{o}\right)+h_{i} \\
0 \leq x \leq 3.6 \\
{\left[\left(-10 \xi^{3}+15 \xi^{4}+6 \xi^{5}\right)\left(h_{i}^{0.705}-h_{o}^{0.705}\right)+h_{i}^{0.705}\right]^{1.418}} \\
6 \leq x \leq 7.3
\end{array}\right.
$$

(a)

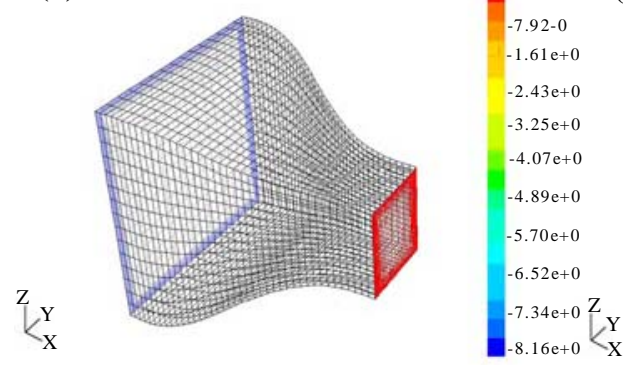

(b)

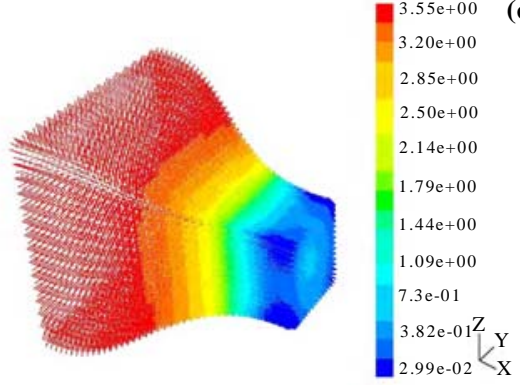

(c)

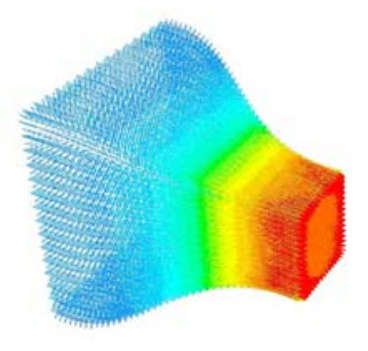

Fig. 6a: a) Grid generation for subsonic wind tunnel contraction; b) Velocity vectors colored by static pressure (Pascal); c) SWT velocity vectors colored by velocity magnitude $(\mathrm{m} / \mathrm{s})$
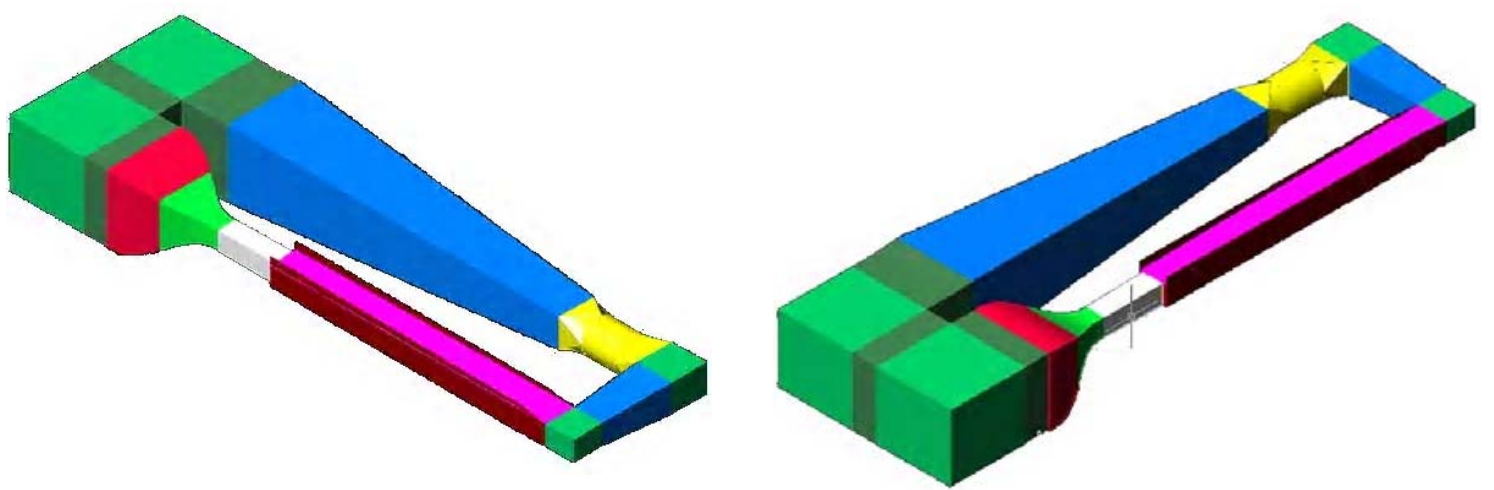

Fig. 7: Designed subsonic wind tunnel 


\section{Computational modeling}

As it was discussed earlier, the flow properties of contraction are identified through the preparation of a $3 \mathrm{D}$ grid generation of contraction profile and their subsequent calculations by a CFD method in Fluent.

The contraction profile scheme illustrated in Figs. $6 a, b$ and $c$ are the pressure and velocity vectors of SWT contraction, respectively.

The total schematics of SWT test section and nozzle application are shown in Fig. 7. Since the long test section of EWT has variable heights, it can be adjusted for the connection of SWT test section end point, but it should be fixed laterally.

\section{CWT contraction}

In contrast to SWT application, the roof profile of the contraction in the CWT process is the same as EWT and only the wall profile should be determined.

Similar to the above-mentioned discussion, CBP program for the CWT with $\alpha=7$ is a good selection for

Table 4: CWT contraction profile

\begin{tabular}{|c|c|c|c|c|c|c|c|c|}
\hline \multicolumn{3}{|c|}{ Climatic WT contraction } & \multicolumn{3}{|c|}{ Climatic WT contraction } & \multicolumn{3}{|c|}{ Climatic WT contraction } \\
\hline $\mathrm{X}$ & Wall (7.0) & Roof & $\mathrm{X}$ & Wall (7.0) & Roof & $\mathrm{X}$ & Wall (7.0) & Roof \\
\hline 0.0 & 2.9100 & 3.2500 & 2.6 & 2.3696 & 2.7334 & 5.2 & 1.2852 & 1.4505 \\
\hline 0.2 & 2.9099 & 3.2496 & 2.8 & 2.2725 & 2.6393 & 5.4 & 1.2418 & 1.3819 \\
\hline 0.4 & 2.9084 & 3.2468 & 3.0 & 2.1728 & 2.5399 & 5.6 & 1.2051 & 1.3221 \\
\hline 0.6 & 2.9033 & 3.2397 & 3.2 & 2.0721 & 2.4364 & 5.8 & 1.1748 & 1.2713 \\
\hline 0.8 & 2.8922 & 3.2266 & 3.4 & 1.9721 & 2.3301 & 6.0 & 1.1504 & 1.2296 \\
\hline 1.0 & 2.8731 & 3.2063 & 3.6 & 1.8744 & 2.2221 & 6.2 & 1.1317 & 1.1969 \\
\hline 1.2 & 2.8448 & 3.1779 & 3.8 & 1.7801 & 2.1138 & 6.4 & 1.118 & 1.1726 \\
\hline 1.4 & 2.8062 & 3.1407 & 4.0 & 1.6905 & 2.0065 & 6.6 & 1.1088 & 1.1560 \\
\hline 1.6 & 2.7569 & 3.0945 & 4.2 & 1.6064 & 1.9014 & 6.8 & 1.1033 & 1.1461 \\
\hline 1.8 & 2.6971 & 3.0391 & 4.4 & 1.5285 & 1.7998 & 7.0 & 1.1008 & 1.1414 \\
\hline 2.0 & 2.6274 & 2.9749 & 4.6 & 1.4572 & 1.7029 & 7.2 & 1.1000 & 1.1401 \\
\hline 2.2 & 2.5486 & 2.9021 & 4.8 & 1.3929 & 1.6118 & 7.3 & 1.1000 & 1.1400 \\
\hline 2.4 & 2.4622 & 2.8213 & 5.0 & 1.3355 & 1.5274 & & & \\
\hline
\end{tabular}

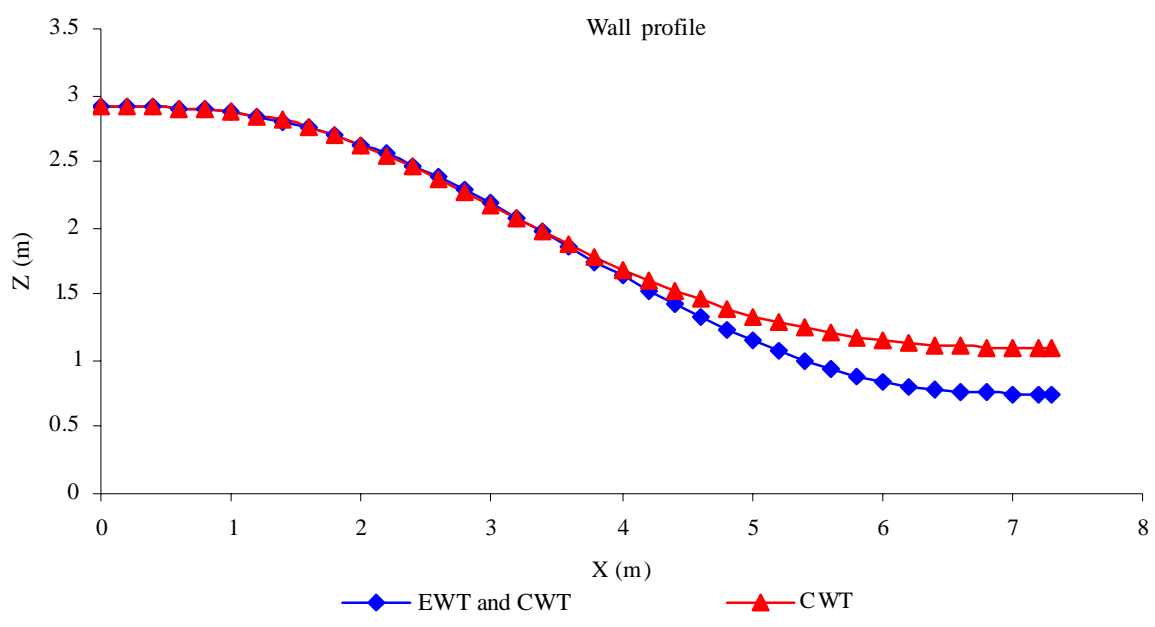

Fig. 8: Wall profile of EWT, SWT and SWT (EWT and SWT profile are the same and CWT profile is fitted to the first part of the EWT profile) 
CWT with $2.28 \mathrm{~m} \times 2.2 \mathrm{~m}$ dimensions (Table 4).

Fig. 8 indicates that the first portion of the CWT wall profile fits exactly on the EWT wall profile. Thus, in the same manner, this portion is designed to be about $50 \%$ of contraction length $(3.6 \mathrm{~m}$ of $7.3 \mathrm{~m}$ of total contraction length) for the SWT application. Therefore, the CWT contraction profile can be shown as:

$h=\left\{\begin{array}{l}\left(-10 \xi^{3}+15 \xi^{4}-6 \xi^{5}\right)\left(h_{i}-h_{o}\right)+h_{i} \\ 0 \leq x \leq 3.6 \\ \left(\left(-10 \xi^{3}+15 \xi^{4}+6 \xi^{5}\right)\left(h_{i}^{1 / 7}-h_{o}^{1 / 7}\right)+h_{i}^{1 / 7}\right)^{7.0} \\ 3.6 \leq x \leq 7.3\end{array}\right.$

\section{Computational modeling}

The CWT grid generation on contraction profile scheme shown in Figs. 9 a, b and c are the velocity and pressure vectors for EWT, respectively. Fig. 10 shows the total schematics of CWT test section and nozzle configuration.

\section{RESULTS AND DISCUSSION}

In the subsonic regimes inside a contraction nozzle, the possibility of air flow separation increases with reduction of air flow velocity (Bell and Mehta, 1998).

Figs. 3b, c; 6b, c and 9b, c show the lowest contraction entrance air flow speed ( $2 \mathrm{~m} / \mathrm{s}$ or less) to check the possibility of separation in the contraction walls. Fig. 11-13 indicate that there is no negative shear stress in the contraction walls with such a low speed. (a)

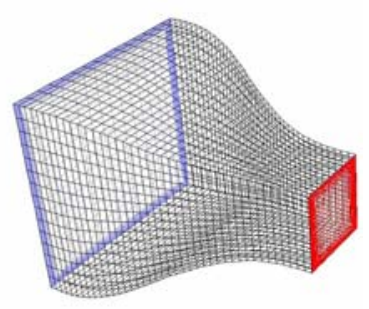

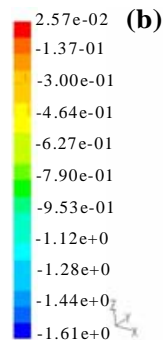

(b)

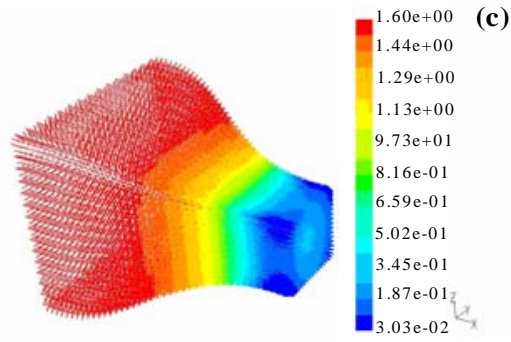

(c)

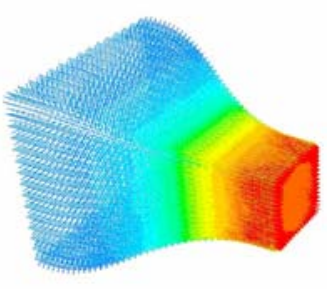

Fig. 9: a) Grid generation for climatic wind tunnel contraction, b) Velocity vectors colored by static pressure (Pascal) c) CWT velocity vectors colored by velocity magnitude $(\mathrm{m} / \mathrm{s})$
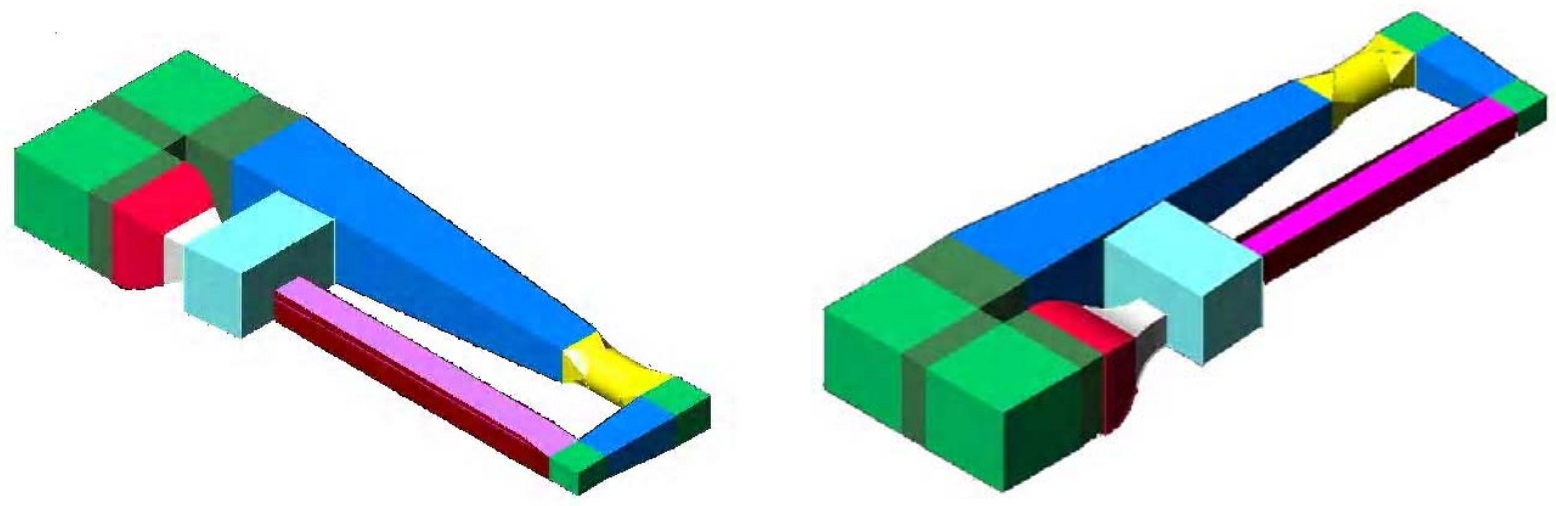

Fig.10: Designed climatic wind tunnel 


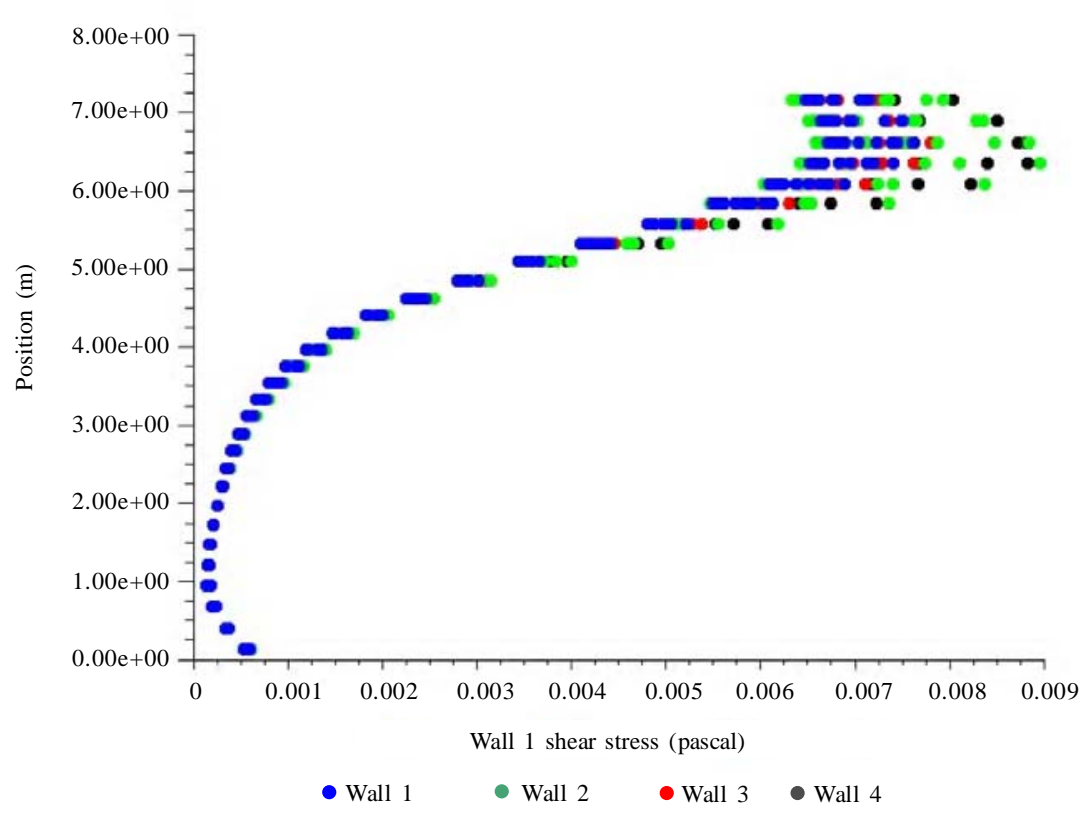

Fig. 11: EWT wall shear stress

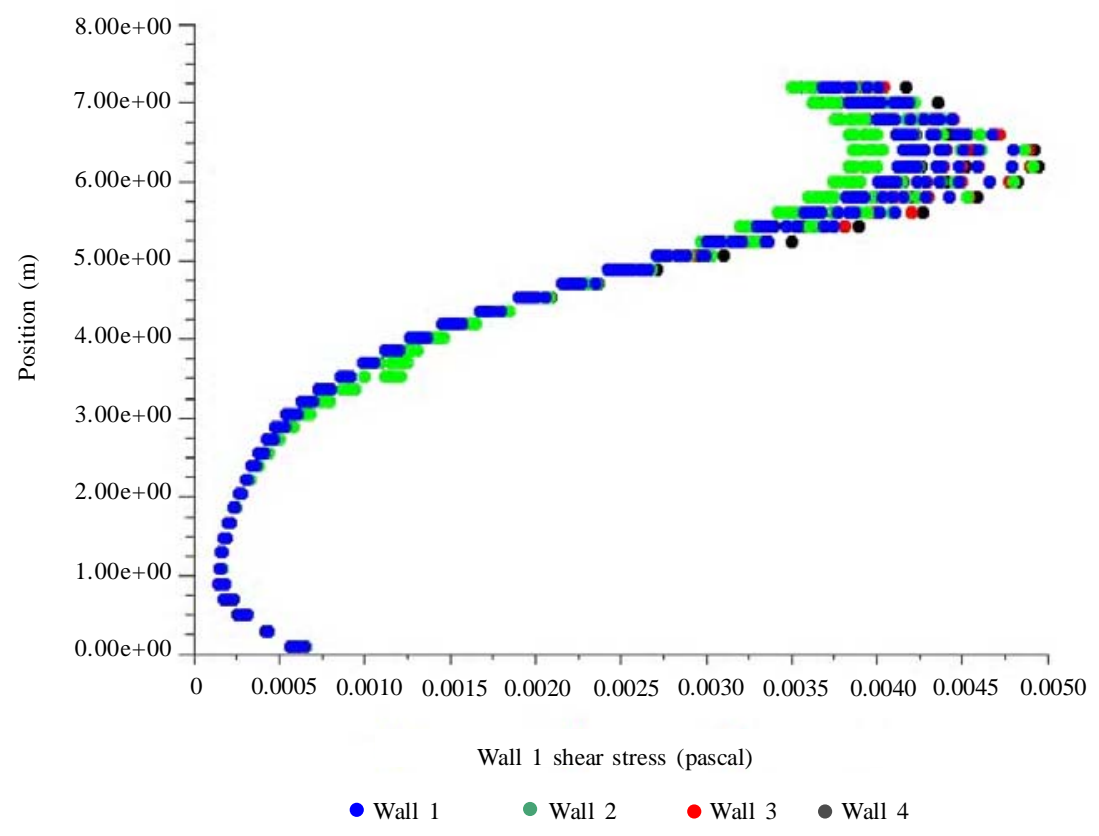

Fig. 12: CWT wall shear stress

Obviously, such a low speed flow is only used in EWT process and is rarely applied in CWT and SWT.

In this paper, several outlet geometries of the contraction are discussed and the proposed technique is also suitable for the existing wind tunnels. The presented technique helped to design a multipurpose wind tunnel with adjustable test section. A CBP (contraction best fit program) and a CFD technique were outcome of this research and can be used to design similar type of tunnels. The wall shear stress 


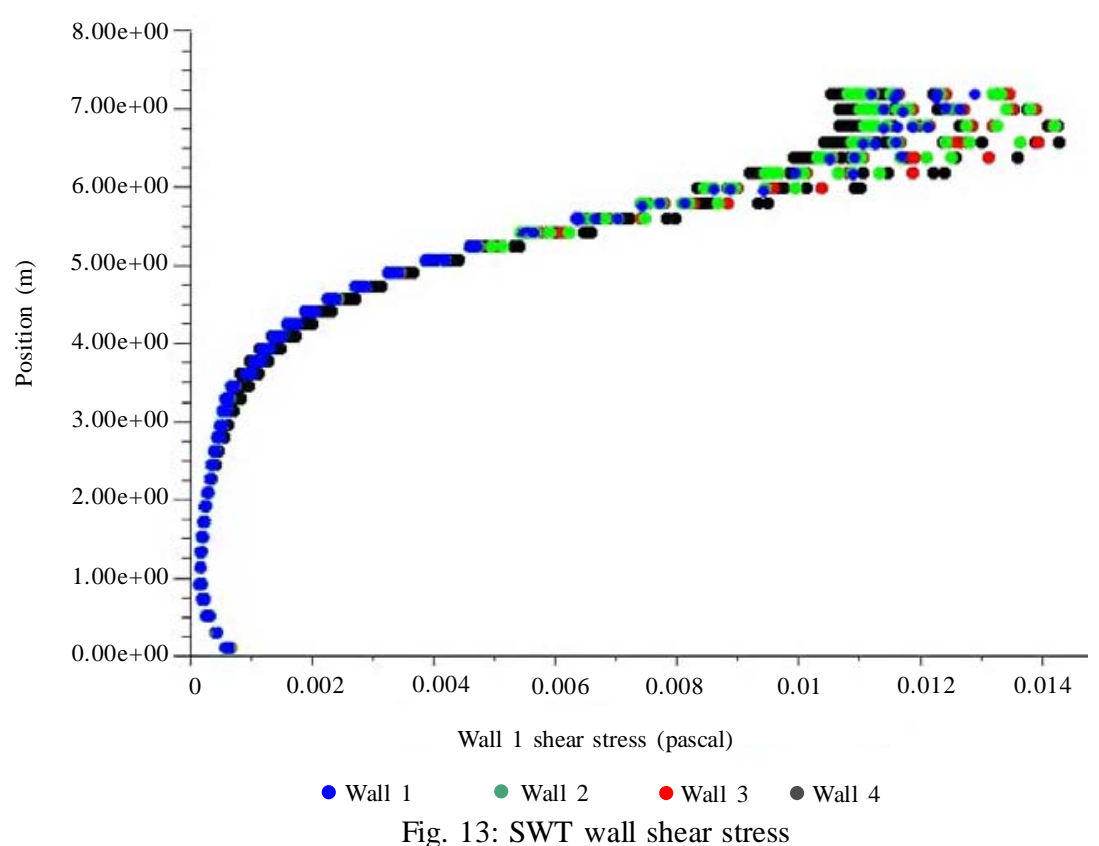

distributions computed along the curved wall of the same contraction section are shown in Figs. 11 up to 13. Initially, the shear stress decreases in the inlet region. This is soon over-whelmed resulting in an increase in shear stress and improvement of boundary layer attachment. The shear stress remains well positive throughout the contraction indicating that separation is not predicted for this particular design. In order to validate the proposed computational scheme, the boundary layer properties in three contractions were compared with the measurements presented by Belland Mehta (1989). The wall shapes for the three contraction sections are plotted in Figs. 3, 6 and 9. For all three contraction shapes, the computations predicted an attached boundary layer along the entire length.

\section{REFERENCES}

Al Nassar, W.; Alhajraf, S.; Al Sudirawi, M.; Joseph, G., (2002). Kisr long atmospheric boundary layer wind tunnel. Proceedings of ICAR5/GCTE-SEN joint conference, international center for arid and semiarid lands studies, Texas tech. university, Lubbock, Texas, USA publication.

Barlow, J. B.; Rae, W. H. J.; Pope, A., (1999). Low-speed wind tunnel testing. John Wiley and Sons, Inc.

Bell, J. H.; Mehta, R. D., (1989). Boundary-layer predictions for small low-speed contractions. AIAA Journal, ISSN 0001-1452, 27 (3), 372-374.
Bell, J. H.; Mehta, R. D., (1998). Contraction design for small low-speed wind tunnels. NASA CR 177488, contract NAS2NCC-2-294.

Bradshaw, P.; Pankhurst, R. C., (1964). The design of lowspeed wind tunnels. NPL aero report 1039.

Brassard, D.; Ferchichi, M., (2005). Transformation of a polynomial for a contraction wall profile. J. Fluid. Eng., 127 (1), 183-185.

Bienkiewicz, B., (1996). New tools in wind engineering. J. Wind Eng. Ind. Aerod., 65 (1-3), 279-300.

Cermak, J. E., (1982). Physical modeling of the atmospheric boundary layer (ABL) in long boundary layer wind tunnel (BLWT). Proceeding of the international workshop on wind tunnel modeling criteria and techniques in civil engineering applications, Gaithersburg, Maryland, USA, Cambridge university press.

Cermak, J. E., (1995). Progress in physical modeling for wind engineering. J. Wind Eng. Ind. Aerod., $3^{\text {rd. Asian-Pacific }}$ symposium on wind engineering J. W., Hong Kong, 54-55, 439-455.

Cermak, J. E., Cochran, L. S., Leffler, R. D., (1995).Windtunnel modeling of the atmospheric surfaces layer. J. Wind Eng. Ind. Aerod., $3^{\text {rd. }}$ Asian-Pacific symposium on wind engineering J. W., Hong Kong, 54-55,505-513.

Cermak, J. E.; Takeda, K., (1985). Physical modeling of urban Air-Pollutant transport. J. Wind Eng. Ind. Aerod., 21 (1), 51-67.

Collar, A. R., (1936). Some experiments with cascades of aerofoils. Reports and Memoranda, No.1768, British A.R.C., 20 .

Cook, N. J., (1982). Simulation technique for short test-section wind tunnel: Roughness, barrier and mixing-device method., Cambridge university press., 126-136. 
Downie, J. H.; Jordinson, R.; Barnes, F. H., (1984). On the design of three-dimensional wind tunnel contractions., Aeronaut. J., 88, 287-295.

Friedman,D.; Westphal, W. R., (1952). Experimental investigation of $90^{\circ}$ cascade diffusing bend with an area ratio of $1.45: 1$ and with several inlet boundary layers., NACA Technical Note 2668.

Garg, R. K.; Lou, J. X.; Kasperski, M., (1997). Some features of modeling spectral characteristics of flow in boundary layer wind tunnels., J. Wind Eng. Ind. Aerod., 72 (1), 1-12.

Hughes, D.; Bohm, M., (2000). A hitch hikers guide to the pye laboratory wind tunnel., Technical report, CSIRO Land and Water publication.

Jordinson, R., (1961). Design of wind tunnel contractions., Aircr. Eng., 33 (392), 294-297.

Kong, L; Parkinson, G. V., (1997). A 3-D tolerant wind tunnel for general wind engineering tests., Proceedings of the $3^{\text {rd. }}$ international colloquium on bluff body aerodynamics and applications, J. Wind Eng. Ind. Aerod., 69-71, 975-985.

Lindgren, B.; Österlund, J.; Johansson, A. V., (1998). Measurement and calculation of guide vane performance in expanding bends for wind-tunnels., Exp. Fluids, 24 (3), 265272.

Morel, T., (1977). Design of two-dimensional wind tunnel contractions. Contributed by fluid engineering division and printed at the joint fluid engineering and lubrication conference, Minneapolis, No. 78-FE-17, ASME J. Fluids Eng. 99, 371-378.

Morel, T., (1975). Comprehensive design of axisymmetric wind tunnel contractions., Contributed by fluid engineering division and printed at the water annual meeting New York, ASME J. Fluids Eng., 97, 225-233.

Nouri, J. A., (1989). Simultaneous measurements of three components of mean velocity and turbulent intensities in a large rectangular turning duct., AIAA $27^{\text {th. }}$ aerospace sciences meeting. January 9-12.

Pankhurst, R. C.; Holder, D. W., (1952). Wind tunnel technique., Sir Isaac Pitman and Sons, Ltd.

Rae, W. H. Jr., Pope, A., (1984). Low-speed wind tunnel testing., John Wiley and Sons Inc., $2^{\text {nd. }}$ Ed.

Sargison, J. E.; Walker, G. J.; Rossi, R., (2004). Design and calibration of a wind tunnel with a two dimensional contraction., Proceedings of the $15^{\text {th. }}$ Australasian fluid mechanics conference the university of sydney, Sydney, Australia.

Schatzmann, M.; Donat, J.; Hendel, S.; Krishan, G., (1995). Design of a low-cost stratified boundary-layer wind tunnel., Journal of Wind Engineering and Industrial Aerodynamics, $3{ }^{\text {rd. }}$ asian-pacific symposium on wind engineering J. W., Hong Kong,54-55, 483-491.

Schlichting, H., (1960). Boundary layer theory., McGraw-Hill.

Vieira, E. D. R.; Aparecido, J. B., (1999). Design and construction of small axisymmetric contractions., In: $5^{\text {a }}$ Reunión do Grupo De Trabajo Sobre Hidromecanica publication, 103-116.

White, B. R., (1996). Physical modeling of atmospheric flow and environmental application, keynote paper, Proceedings of the $51^{\text {st. }}$ anniversary conference of korean society of mechanical engineers, Pusan national university, Korea.

\section{AUTHOR (S) BIOSKETCHES}

Abbaspour, M., Ph.D., Professor, Department of Mechanical Engineering, Sharif University of Technology and Graduate School of the Environment and Energy, Science and Research Branch, Islamic Azad University, Tehran, Iran. Email: m-abbaspour@jamejam.net

Shojaee, M. N., Ph.D. student, Department of Environmental Engineering, Graduate School of the Environment and Energy, Science and Research Branch, Islamic Azad University, Tehran, Iran.

Email:nimashojaee@yahoo.com

This article should be referenced as follows:

Abbaspour, M.; Shojaee, M. N., (2008). Innovative approach to design a new national low speed wind tunnel. Int. J. Environ. Sci. Tech., 6 (1), 23-34. 